\title{
The effect of substrate temperature on chemical reactions during GaN growth in a vertical MOCVD
}

\author{
Feng Lansheng ${ }^{1 a}$,Guo Runqiu ${ }^{16}$, Zhang Jincheng ${ }^{20}$ \\ (1. School of Electro-Mechanical Engineering,Xidian Univ.,Xi'an 710071,China ; \\ 2.School of Microelectronics, ,Xidian Univ.,Xi'an 710071,China)

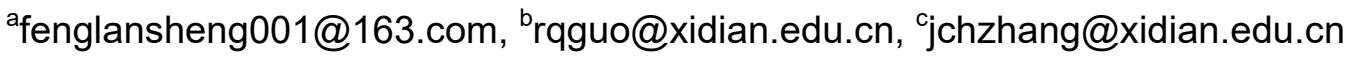

Keywords: GaN; MOCVD; substrate temperature; reaction kinetics

\begin{abstract}
A model on GaN growth in a vertical MOCVD system is presented. Simulations on the GaN growth using the model are carried out under different substrate temperatures. The result shows that during the gas phase translation of the reactants, the adduct reactions decreased and the pyrolytic reactions are strengthened when the substrate temperature rises up. The growth rate of $\mathrm{GaN}$ is accelerated by pyrolytic reactions. When the temperature is above $800^{\circ} \mathrm{C}$, the etching reactions of hydrogen on $\mathrm{GaN}$ become obvious, which decreases the GaN growth rate. The result shows that the optimal temperature for $\mathrm{GaN}$ growth is about $1000^{\circ} \mathrm{C}$. And a comparison is made between simulation result and experimental data at $1000^{\circ} \mathrm{C}$, which prove the validity of the simulation.
\end{abstract}

\section{Introduction}

$\mathrm{GaN}$ is an important wide band-gap semiconductor. It is widely used in photoelectric devices, high power devices, etc. MOCVD(Metal Organic Chemical Vapor Deposition) is the main method to produce high quality $\mathrm{GaN}$ materials at present. The substrate temperature during $\mathrm{GaN}$ growth in MOCVD is one of the most important parameters which will determine the material quality. To improve the quality of GaN material, many researchers have done a lot of work on GaN growth. Chien-Fu Tseng[1-2] carried out simulations on gas flow in a MOCVD chamber and surface reactions in GaN growth. Yu HaiQun[3-6] analyzed the chemical reaction process during the GaN growth. The simulations on GaN growth are mainly attributed to physical filed analysis or chemical reaction process at present. The chemical reaction process is so complex that the researchers have not made an universal model yet. This work made a model on GaN growth in a MOCVD system used to simulate the gas flow and chemical reactions during GaN growth. On this basis, simulations have been taken with FLUENT to analyze the effect of substrate temperature on GaN growth.

\section{The model used in GaN simulation}

In general, the chemical reactions during $\mathrm{GaN}$ growth can be divided into adduct reactions and pyrolytic reactions. The adduct reactions will occur when the reactant gas get into the chamber and mix together immediately in gas phase translation. The pyrolytic reactions will only occur when the temperature is high enough. Table 1 indicates the gas phase reactions during GaN growth in a vertical MOCVD system which is used in this work.

Table 1 Gas Phase Reactions in GaN Growth

\begin{tabular}{|c|c|c|c|c|}
\hline NO. & Gas Phase Reactions & $\mathbf{A}$ & $\mathbf{n}$ & Ea \\
\hline 1 & $\mathrm{Ga}\left(\mathrm{CH}_{3}\right)_{3} \longrightarrow \mathrm{Ga}\left(\mathrm{CH}_{3}\right)_{2}+\mathrm{CH}_{3}$ & $3.47 \mathrm{e} 15$ & $\mathbf{0}$ & $2.4895 \mathrm{e} 8$ \\
\hline 2 & $\mathrm{Ga}\left(\mathrm{CH}_{3}\right)_{3}+\mathrm{NH}_{3} \longrightarrow \mathrm{Ga}\left(\mathrm{CH}_{3}\right)_{3}: \mathrm{NH}_{3}$ & $1 \mathrm{e} 9$ & $\mathbf{0}$ & $\mathbf{0}$ \\
\hline 3 & $\mathrm{GaCH}_{3}+\mathrm{NH}_{2} \longrightarrow \mathrm{GaN}+\mathrm{CH}_{3}$ & $6.6 \mathrm{e} 13$ & $\mathbf{0}$ & $1.6628 \mathrm{e} 8$ \\
\hline 4 & $\mathrm{CH}_{3}+\mathrm{H}_{2} \longrightarrow \mathrm{CH}_{4}+\mathrm{H}^{+}$ & 0.29 & 3.1 & $3.6401 \mathrm{e} 7$ \\
\hline 5 & $\mathrm{NH}_{3}+\mathrm{H}^{+} \longrightarrow \mathrm{NH}_{2}+\mathrm{H}_{2}$ & 540 & 2.4 & $4.1487 \mathrm{e} 7$ \\
\hline 6 & $\mathrm{NH}_{3}+\mathrm{CH}_{3} \longrightarrow \mathrm{NH}_{2}+\mathrm{CH}_{4}$ & 3.31 & 2.51 & $4.1254 \mathrm{e} 7$ \\
\hline 7 & $\mathrm{Ga}\left(\mathrm{CH}_{3}\right)_{2} \longrightarrow \mathrm{GaCH}_{3}+\mathrm{CH}_{3}$ & $8.7 \mathrm{e} 7$ & $\mathbf{0}$ & $1.481 \mathrm{e} 8$ \\
\hline
\end{tabular}

The chemical reactions listed in Table 2 include all possible reactions that may occur on the surface of the substrate during GaN growth. 
Table 2 Surface Reactions in GaN Growth

\begin{tabular}{|c|c|c|c|c|}
\hline NO. & Surface Reactions & $\mathbf{A}$ & $\mathbf{n}$ & $\mathbf{E a}$ \\
\hline 1 & $\mathrm{Ga}\left(\mathrm{CH}_{3}\right)_{3}+\mathrm{NH}_{3} \longrightarrow \mathrm{GaN} \_\mathrm{b}+3 \mathrm{CH}_{4}$ & 1 & $\mathbf{0}$ & $\mathbf{0}$ \\
\hline 2 & $\mathrm{Ga}\left(\mathrm{CH}_{3}\right)_{3}: \mathrm{NH}_{3} \longrightarrow \mathrm{GaN} \_b+3 \mathrm{CH}_{4}$ & 1 & $\mathbf{0}$ & $\mathbf{0}$ \\
\hline 3 & $\mathrm{GaN} \longrightarrow \mathrm{GaN}$ b & 1 & $\mathbf{0}$ & $\mathbf{0}$ \\
\hline 4 & $\mathrm{GaCH}_{3}+\mathrm{NH}_{3} \longrightarrow \mathrm{GaN} \_\mathrm{b}+\mathrm{CH}_{4}$ & 1 & $\mathbf{0}$ & $\mathbf{0}$ \\
\hline 5 & $\mathrm{Ga}\left(\mathrm{CH}_{3}\right)_{2}+\mathrm{NH}_{3} \longrightarrow \mathrm{GaN} \mathrm{b}+2 \mathrm{CH}_{4}$ & 1 & $\mathbf{0}$ & $\mathbf{0}$ \\
\hline 6 & $\mathrm{Ga}+\mathrm{NH}_{3} \longrightarrow \mathrm{GaN} \_\mathrm{b}+\mathrm{H}_{2}^{-}$ & 1 & $\mathbf{0}$ & $\mathbf{0}$ \\
\hline 7 & $\mathrm{GaN} \_b+\mathrm{H}_{2} \longrightarrow \mathrm{Ga}+\mathrm{NH}_{3}$ & 1 & $\mathbf{0}$ & $\mathbf{0}$ \\
\hline
\end{tabular}

The reaction rate of each chemical reaction in table 1 is determined by Arrhenius equation: $\mathrm{k}=\mathrm{AT}^{\mathrm{n}} \exp \left(-\mathrm{E}_{\mathrm{a}} / \mathrm{RT}\right)$. The unit of coefficient $\mathrm{A}$ is $\left[\mathrm{cm}^{3} /\left(\mathrm{mol}^{*} \mathrm{~s}\right)\right]$ and $\mathrm{n}$ is exponent of temperature T. $\mathrm{E}_{\mathrm{a}}$ is the activation energy of the reaction, whose unit is $[\mathrm{j} / \mathrm{kgmol}]$. $\mathrm{R}$ is ideal gas constant.

The simulations of chemical reaction process during GaN growth in this work are on the basis of chemical reaction model listed in Table 1 and Table 2.

The MOCVD system used in this work is 120-MOCVD developed by XIDIAN University. Its chamber structure is shown in figure 1(a). And the geometric model used to simulate physical filed is shown in figure 1(b). The geometry parameters of this model includes: radius of substrate is $25 \mathrm{~mm}$, radius of gas entrance is $25 \mathrm{~mm}$, and the distance from gas entrance to substrate is $225 \mathrm{~mm}$.

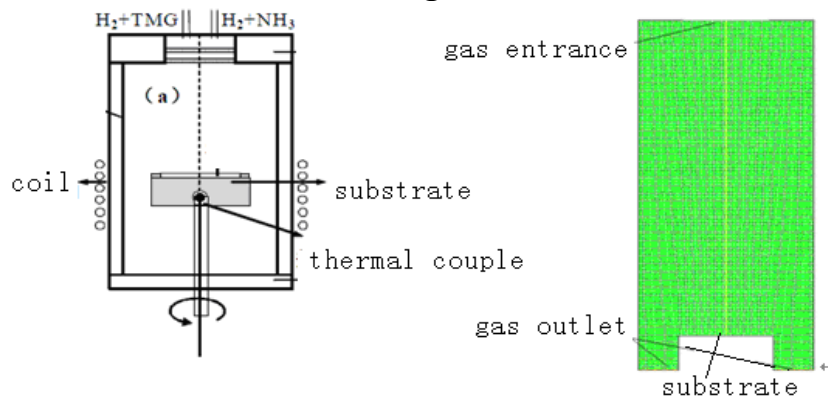

(a)

(b)

Figure 1 120-MOCVD chamber and geometry model

\section{Results and Discussion}

Simulations on GaN growth under different substrate temperatures are carried out on the basis of model built before. Other boundary conditions are listed as followed: chamber pressure is 40 torr, reactant gas are TMGa $\left(\mathrm{Ga}\left(\mathrm{CH}_{3}\right)_{3}\right), \mathrm{NH}_{3}$ and the carrier gas is $\mathrm{H}_{2}$. The ratio of V/III is 2000.The velocity of gas flow inlet at entrance is $0.3 \mathrm{~m} / \mathrm{S}$.

\section{The effect of substrate temperature on the Gas Phase translation}

The reactions during the gas phase translation contain the adduct reactions and the pyrolytic reactions. The degree of adduct reactions can be characterized by the percentage of $\mathrm{TMGa}: \mathrm{NH}_{3}$ according to gas phase chemical reaction model. And the products of pyrolytic reactions are mainly $\mathrm{DMGa}\left(\mathrm{Ga}\left(\mathrm{CH}_{3}\right)_{2}\right)$ and $\mathrm{MMGa}\left(\mathrm{GaCH}_{3}\right)$. The mass fraction of $\mathrm{TMGa}: \mathrm{NH}_{3}, \mathrm{DMGa}$ and $\mathrm{MMGa}$ along the axis of chamber is shown in figure 2 under different substrate temperatures according to the simulation results.

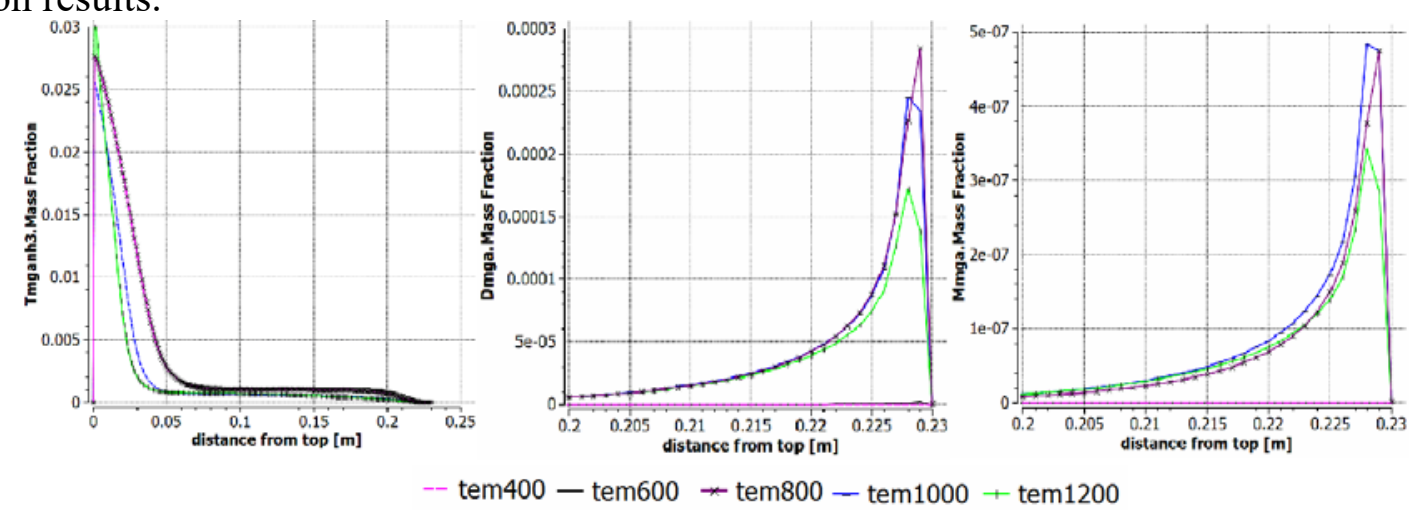

Figure 2 The mass fraction of TMGa: $\mathrm{NH}_{3}, \mathrm{DMGa}$ and MMGa along the axis of chamber 
As can be seen from figure 2, the mass fraction of TMGa:NH3 rises rapidly near the gas entrance where the temperature is not very high. Which means the adduct reaction of TMGa and $\mathrm{NH}_{3}$ occurred rapidly when the reactant gases mix together. Then the reactant gases are translated toward the substrate and the temperature grows higher gradually. The mass fraction of DMGa and MMGa increase rapidly when the temperature is above $600{ }^{\circ} \mathrm{C}$, and the mass fraction of TMGa: $\mathrm{NH}_{3}$ decreases at the same time. That means the pyrolytic reactions is accelerated by temperature. According to figure 2, the mass fraction of DMGa reaches its maximum when the temperature is about $800^{\circ} \mathrm{C}$ and MMGa reaches its maximum when the temperature is about $1000^{\circ} \mathrm{C}$.

\section{The effect of substrate temperature on the surface reaction}

The GaN growth rate and material quality are mainly determined by the surface reaction process and reaction rate. The mass fractions of TMGa, DMGa and $\mathrm{MMGa}$ along the radius of substrate are shown in figure 3. It can be seen that the distribution of DMGa and MMGa are similar to each other. The mass fraction is very small when the temperature is under $600^{\circ} \mathrm{C}$ because the pyrolytic reactions is weak. When the temperature is above $800^{\circ} \mathrm{C}$, the mass fraction of DMGa and MMGa also decrease when the temperature rises up. The reason is that the reactions producing GaN from DMGa and MMGa are accelerated by temperature. The distribution of TMGa along the radius of substrate is also shown in figure 3. It can be seen that the mass fraction of TMGa decreases with the temperature increasing which because the pyrolytic reaction of $\mathrm{TMGa}$ increases. When the temperature rises above $1000^{\circ} \mathrm{C}$, the mass fraction of TMGa is negligible, which means the pyrolytic reaction of TMGa is enough.

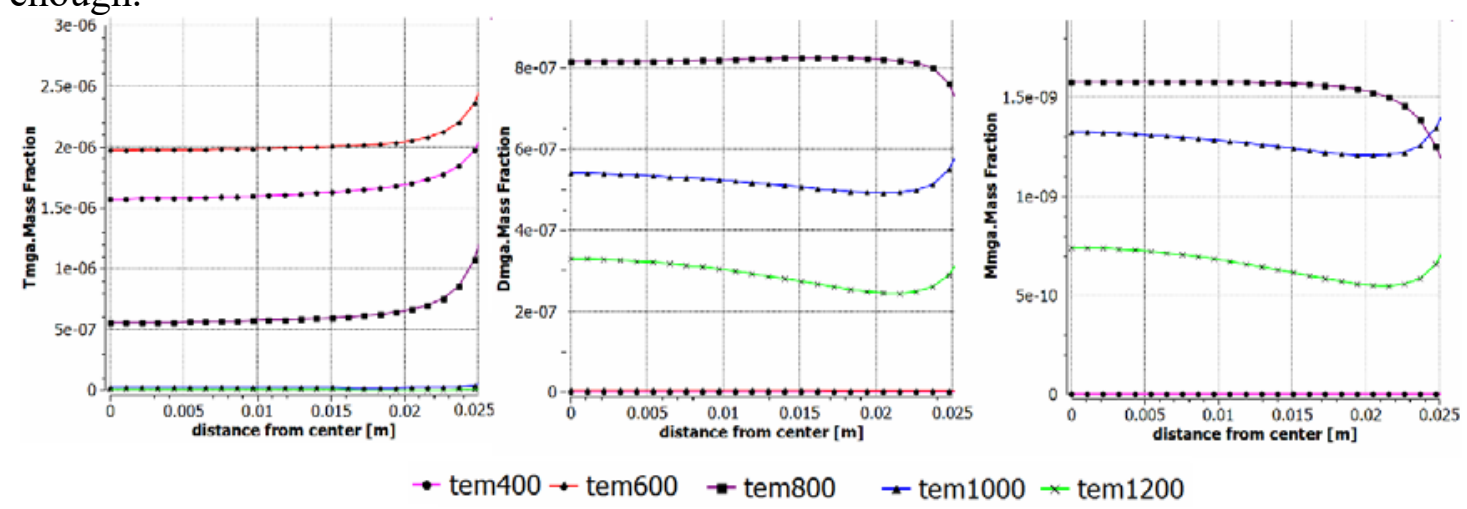

Figure 3 distribution of TMGa,DMGa and MMGa along the radius of substrate

The distribution of TMGa: $\mathrm{NH}_{3}$ and $\mathrm{GaN}$ particles along the radius of substrate are shown in figure 4. According to the reaction model, the GaN growth rate is mainly determined by the mass fraction of $\mathrm{GaN}$ particle. The mass fraction of $\mathrm{GaN}$ is negligible when the temperature is below $600^{\circ} \mathrm{C}$. $\mathrm{GaN}$ particles start to appear when the temperature is above $800^{\circ} \mathrm{C}$ and reach its maximum when the temperature is about $1200^{\circ} \mathrm{C}$. During the same process, the mass fraction of $\mathrm{TMGa}_{\mathrm{NH}}$ decreases with temperature increasing.

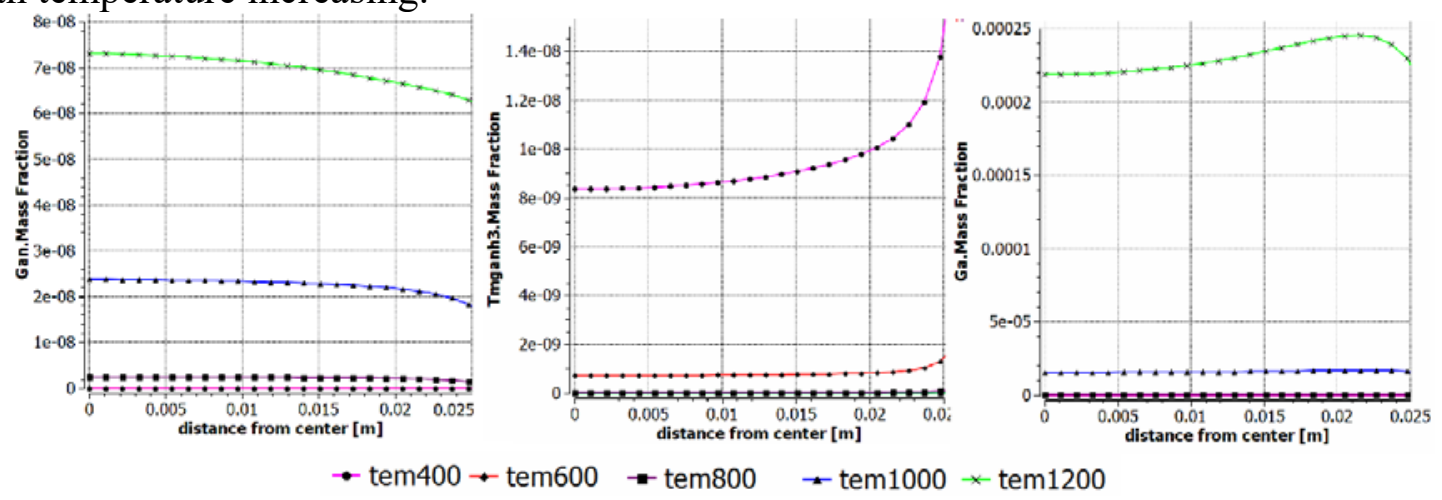

Figure 4 distribution of $\mathrm{GaN}, \mathrm{TMGa}: \mathrm{NH}_{3}$ and $\mathrm{Ga}$ along the radius of substrate

Beside the adduct reactions and the pyrolytic reactions mentioned before, the etching reaction of hydrogen on $\mathrm{GaN}$ will also occur during surface reactions according to the surface reaction model. The etching reaction on the surface will decrease the GaN growth rate by taking Ga atom away from 
material surface. The main product of the etching reaction is Ga atom. The distribution of Ga atom along the radius of substrate is shown in figure 4 under different substrate temperature. It can be seen that the mass fraction of $\mathrm{Ga}$ atom become obvious when the temperature is above $1000^{\circ} \mathrm{C}$ and is negligible when the temperature is blow $800^{\circ} \mathrm{C}$. So the influence on $\mathrm{GaN}$ growth rate of the etching reaction will only appear when the temperature is above $1000^{\circ} \mathrm{C}$.

\section{Simulation result on $\mathrm{GaN}$ growth rate}

On the basis before, this work carried out a simulation with parameters below: the substrate temperature is $1000^{\circ} \mathrm{C}$, the chamber pressure is 40 torr, the reactant gases are $\mathrm{TMGa}, \mathrm{NH}_{3}$ and the carrier gas is $\mathrm{H}_{2}$, the ratio of $\mathrm{V} / \mathrm{III}$ is 2000 , the gas flow inlet speed is $0.3 \mathrm{~m} / \mathrm{S}$. The distribution of GaN growth rate along the radius of substrate according to the simulation is shown in figure 5, which is compared to an experimental data with the same parameter. It can be seen that the two results coincide basically. This proves the reliability of the simulation model and the simulation method.

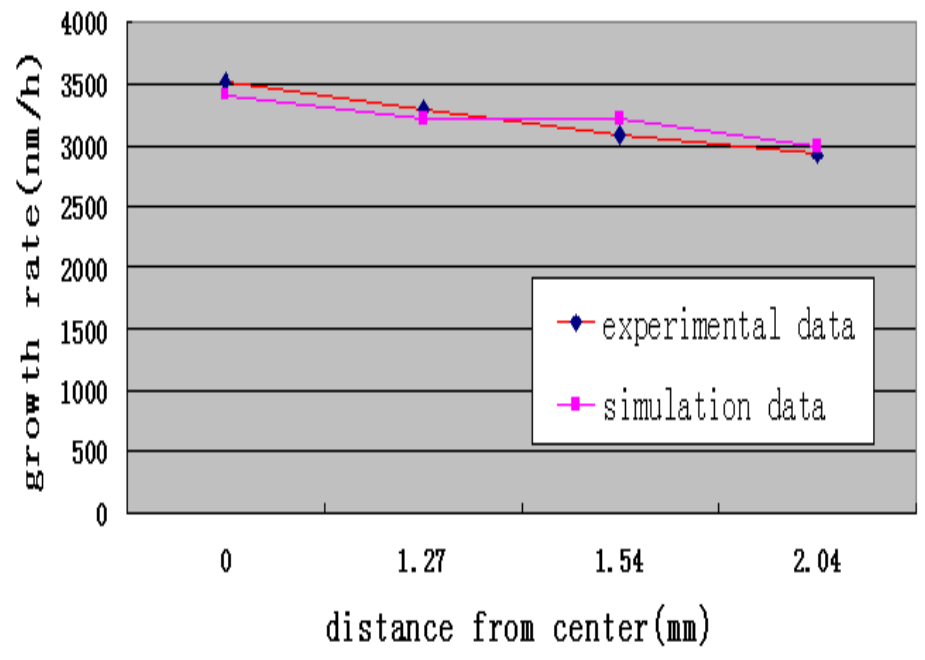

Figure 5 growth rate from simulation and experiment

\section{Conclusion}

Simulations on the GaN growth are presented on the basis of chemical reaction model and geometric model built in this work. The results show that the adduct reactions decreased and the pyrolytic reactions are strengthened when the temperature rises up during gas phase translation. The pyrolytic reactions become obvious when the temperature is above $600^{\circ} \mathrm{C}$. And the $\mathrm{GaN}$ growth rate rises up with substrate temperature when the temperature is below $1000^{\circ} \mathrm{C}$. When the temperature is above $800^{\circ} \mathrm{C}$, the etching reaction of hydrogen on GaN began to appear which will reduce the GaN growth rate. According to the simulation, the optimal substrate temperature is about $1000^{\circ} \mathrm{C}$.

\section{References}

[1] Chien-Fu Tseng, Tsung-Yen. Journal of Crystal Growth,2015,432: 54-63

[2] Zhi Zhang, Haisheng Fang. Applied Thermal Engineering,2015, 91: 53-61

[3] YU Haiqun. Materials Review,2012,26(9)21-24

[4] Wang Guobin.Journal of Crystal Growth, Supplem ent June, 2010,139:160-163

[5] Rinku P. Parikh, Raymond A. Adomaitis. Journal of Crystal Growth, 2006, 286: (2006) 259-278

[6] K. Fu, Y. Fu, P. Han. Journal of Applied Physics,2008, 103, 